\title{
Major Challenges in the Implementation of AADHAAR Enable Fertilizer System and Perception of Farmers and Retailers About ePoS (A Case Study of Kanpur District, Uttar Pradesh State)
}

\author{
Ravi Kumar Raman*, Ashish Singh and Manjeet Kumar Verma \\ Institute of Management Studies, Banaras Hindu University, Varanasi \\ (Agribusiness, RGSC, BHU), India \\ *Corresponding author
}

Ke y w o r d s
ePoS, UIDAI
Server,
Authentication,
Fertilizer and
Initiative
Article Info
Accepted:
15 January 2020
Available Online:
10 February 2020

Keywords

ePoS, UIDAI

Server,

Authentication,

Fertilizer and

Initiative

Article Info

Accepted:

Available Online:

10 February 2020

\section{A B S T R A C T}

Availability of fertilizer on the peak season of cultivation is a very big problem in our country due to less production and black marketing of fertilizer, especially nitrogenous fertilizer. So, government of India now adopted a digital initiative under which now fertilizer being sold through Electronic Point of Sale $(e P o S)$ system with integration of digital records of beneficiaries. The Aadhaar enabled Fertilizer Distribution System $(A e F D S)$ is a potential to streamline subsidies to actual beneficiaries and also facilitate in releasing subsidies to fertilizer companies based on the actual sales made. The ePoS device retrieves information from UIDAI server, Webland server \& SHC server for authentication and transactions are made through the Biometrically Authenticated Physical uptake (BAPU) model. Govt. of India has chosen the Krishna district's (Andhra Pradesh state) model of implementation for piloting DBT in fertilizers in 16 districts across the country. This research paper mainly focuses on farmers' knowledge and awareness about Aadhaar enabled Fertilizer Distribution System (AeFDS) and retailer thinking about it.

\section{Introduction}

The word agriculture two words 'Ager'+ 'culture', where Ager is a Latin word which means Land or field and word Culture means cultivation or farming. It means the agriculture is the process of growing crop and livestock for the benefit purpose. The practiced of agriculture is throughout the world because with food people can't survive on the earth and food only can obtain through farming.

Agriculture is not only cultivation of grain it is all about flower, forest, food, fabric, and farming, so we can say that these are 5F'S of agriculture. In the ancient time man become settle at that place where cultivation of crop 
was good because at that time traditional cultivation was the only source for the survival.

In India agriculture is the main source or we can say back bone of Indian economy because in India about 50 percent population depend on the agriculture and without agriculture growth India cannot achieve their $9-10 \%$ GDP growth.

Population of world also growing day to day in this way requirement of food for fulfill of the need of big population demand of food also increasing day to day but on our earth area for the cultivation is fix that is not growing so to the fulfill the requirement of the food for the people with changing time method of farming also changing so that maximum produce can be taken.

In the ancient time farmers was only depend on the rain water, organic fertilizer traditional seed etc. we can say that farming was only depend on manpower and animal. But in the scientific era due to innovation of new technology like different type of fertilizer for the increasing production and for the protection of crop from different insect and pest, high yielding verity of crop seed, different type of mercenary that is use full for the different farming operation that can decrease human labour and are capacity to maximize the produce.

The governments of both the level i.e. central and state level also trying to incentivize to the person who is involve in the any type of the farming process so that productivity can be improve and ensure food security in the country. Governments are trying to intervention by crop diversification and through sustainable agriculture in different crop like oilseed and pulses with inputintensive policies and regionally concentrated programmers.

\section{About Kanpur district (research place)}

The population of Kanpur district is about 6,377,452 (According to 2011 census). The literacy rate was 84.14 per cent and sex ratio was 842.Average rainfall is $840 \mathrm{~mm}$ and temperature goes maximum $47.8^{\circ} \mathrm{C}$ in summer and goes minimum $4^{0} \mathrm{C}$ in winter. Net sown area 188900 ha and net irrigation area 151300 ha.

Major farming system Rice-wheat \& RiceMustard, Jowar-wheat \&Bajra - Wheat, Ricegram \& Maize- potato-wheat, Maize-Pigeon Pea \& Rice Toria Wheat etc. Soil type Alluvial Soil, loamy sand and well drained. Major crop wheat, rice, Maize, Bajra, Jowar, Pea, Gram, Pea, Potato, Mustard, Moong etc.

The study on the basis of the following objectives includes, to know the awareness about Point of sale (ePOS) system among retailers and farmers. To know the retailers perception about point of sale (ePOS). And also to know the impact of POS machine in direct benefit transfer (DBT).

\section{Knowledge about fertilizer}

Fertilizer is a substance that naturally occurring in the soil and also manufacture in the factories, which provide one or more nutrient element to the plant (FAO, 1985) which is require for the growth and survival. In another word we can say that fertilizer is the food for plants.

Plants requires 17 essential nutrients for the survival, but the most important for the plant is $\mathrm{N}$ (Nitrogen), $\mathrm{P}_{2} \mathrm{O}_{5}$ (Phosphate), $\mathrm{K}_{2} \mathrm{O}$ (Potassium) which require in higher amount for the development of the plant. Fertilizer is made from both private as well as public sector companies. Price of the fertilizer is controlled by the central government. The subsidy which is given on the fertilizer that is 
directly transferred to the manufacturer and farmer purchase on subsidized price.

\section{Status of Indian fertilizer industries}

India's position in global fertilizer market indicates that India is an important player in the world fertilizer market.

India is the $2^{\text {nd }}$ largest consumer of fertilizers after China.

India also ranks $2^{\text {nd }}$ in the production of nitrogenous fertilizers and $3^{\text {rd }}$ in phosphatic fertilizers.

It is the second biggest consumer of nitrogenous and phosphatic fertilizers after China (14.1 per cent and 14.5 per cent respectively of world consumption in 2012 for nitrogenous and phosphatic fertilizers) and the fourth biggest consumer of potassic fertilizers after China, Brazil and USA (7 per cent of world consumption in 2012).

According to the Food and Agriculture report world demand for total fertilizer nutrients is estimated to grow at $1.8 \%$ per annum from 2014 to 2018. The fertilizer industry is considered to be an allied activity of the Agricultural sphere. Farming and ancillary activities contribute about 1/6th to India's GDP.

Being an important industry to the Indian economy, the government has ensured the availability of adequate quantity and proper quality of fertilizers to the farmers. Also, to make sure adequate control over its quality, price and distribution, the industry is highly regulated under the Fertilizer Control Order, 1985.

\section{Production of fertilizer in India}

32 Large sized Urea Manufacturing units,

21 DAP and Complex Fertilizers units and

2 units which manufacture Ammonium
Sulphate as a By- Product.

110 medium and small scale units in operation producing Single Super Phosphate (SSP).

\section{Direct transfer benefit in the fertilizer industry}

The introduction of Direct Transfers Benefit in the Fertilizer Industry has been a boon to the fertilizer sector. Under the DBT scheme the subsidy will be released to the fertilizer companies instead of the beneficiaries, after the sale is made by the retailers to the beneficiaries. When DTB was introduced first in the fertilizer industry the subsidy was given on the dispatch of the materials was from their respective factories.

After a few revisions, on the disbursement of the fertilizers the subsidy was getting paid at a railhead point or any approved godown of a district. Now under the new system, payment of subsidy is to be based on weekly settlement of claims from actual sales data captured on POS machines after the sale is made by the retailers to the beneficiaries on submission of claims generated in the web-based online Integrated Fertilizer Monitoring System (iFMS) by fertilizer companies.

\section{E-PoS(Point of Sale) system and their working process}

E-PoS stand for Electronic Point of Sale. It is a digital and computerized system used in shops, restaurants and other retail outlets. Essentially it's an electronic way of letting people pay for goods or services.

E-PoS systems have a variety of uses such as,

- Helping to improve the way a business performs.

- Allows information and stock to be stored securely.

- Information can be retrieved immediately as 
and when needed.

- Allows a business to see what products are in demand.

- It can print out receipts and vouchers for customers immediately.

- It can also be linked to a company website or any terminal within the business.

E-PoS system comprises of computer hardware, peripherals and software perfectly suited to a point of sales environment. For example, some of the most common components to an E-PoS system are cash draws, chip and pin, customer displays, keyboards, printers and weighing scales.

It's a system that can support data entry through a variety of devices such as computer keyboards, touch screen monitors and barcode scanners. It gives the retailer tremendous flexibility in choosing specific peripherals for their business - i.e. in a high demand environment such as a supermarket. An EPoSsystem can be configured to work in tandem with barcode scanners to ensure price accuracy and allowing the staff to work quickly.

Benefits of using an E-PoS system?

- Highly secure and fast transaction process

- Provides accurate sales reporting

- Providing accurate price information

- Inventory tracking

- Quick Report generation

- Fingerprint authentication

- Improves data integrity by keeping track of sales and taxes

- Manipulation is not possible because manual entry is not required

From June 2017 onwards, the government has decided to pay Rs 70,000 Crore fertilizer subsidy budgeted for 2017-18 will be disbursed to the manufacturers only after sale of soil nutrients via PoS devices at retail level.
It will help to reduce the government's fertilizer subsidy bill by up to 20 percent through plugging diversion and leakages of subsidized fertilizers.

Elaborating more on the new system, the official said that fertilizer will be sold after identifying the beneficiary farmers through Aadhaar-based biometric authentication, voter ID or Kisan Credit Card. The sales transaction as well as buyer details would be captured in the PoS machine installed at the retailer's end and connected with a central server.

The companies will have to bear the installation cost of PoS devices. In fact, they can spend the fund of Rs 50 per tonne that the government gives them to acknowledge the sale receipts.

Fertilizer companies have been given a deadline of May 31st for procurement and installation of PoS machines at all the 2 lakhodd registered outlets selling to farmers. All transactions thereafter will have to be done through PoS machines in order to be able to claim subsidy. DBT system will provide a complete track of the consumption pattern.

\section{Research Methodology}

The date for present study on the point of sale (ePoS) collected by two methods i.e. from farmers through group discussions and questionnaire method and also from the retailers through questionnaire in different area of Kanpur district.

The research methodology followed is descriptive research. It includes surveys and fact finding enquiries.

Research design: Descriptive research Area of survey: Kanpur District Sampling elements: Retailer \& Farmer Sampling technique: Group discussions and questionnaire method 
Population size: Kanpur- 29.2 Lakh (a/c to2011 census)

No. of Farmers: 450

No. of retailers: 57

Data collection: Done through primary and secondary data

Primary data: Collected through wellstructured questionnaire, group discussions and personal interview

Secondary data: Collected using journals, articles, books, websites etc.

\section{Research design: descriptive research}

The research is to describe the data and characteristics about what is being studied. The idea behind this type of research is to study frequencies, averages, and other statistical calculations. Although this research is highly accurate, it does not gather the causes behind a situation.

Descriptive research is mainly done when a researcher wants to gain a better understanding of a specific topic. Descriptive research is the exploration of the existing certain phenomena. The details of the facts won't be known. The existing phenomena's facts are not known to the person.

\section{Earlier case studies}

Many students and researcher have been studies on different areas of marketing's and other sectors. Here some studies of different workers are given with their topics in relation to their case studies in different area of the research.

V.C. Patil and et al., (2008) "Adoption of Information and Communication Technology (ICT) for Agriculture: An Indian case study" has characterized major changes in the Information and Communication Technology (ICT) environment in agriculture worldwide in the past decade.
The changes have brought adoption of on farm information management facilities, computer embedded process control devices, remote sensing with spatial data utilization, and more, with almost all of them endowed with communication capabilities.

M. V. Victoria (2007) "Agricultural technology in Bangladesh: a study on nonfarm labor and adoption by gender" .The paper particularly looks at the effects of HYV adoption on time allocation and labor force participation of men and women in non-farm activities.

B. B. Singh (2007) Agricultural Extension Education Diffusion and Adoption of Agricultural Innovations has explained the main dependent and independent factors in adoption process. The study has also "determined rate of adoption of innovations is impacted by five factors i.e. relative advantage, compatibility, trialability, observability, complexity.

All these studies were helpful for future planning for the government. This type of studies plays an important role for understanding about profit and loss of a particular technology and marketing in ground level.

Here some data of the study are given in tables with questionnaire

Farmers' Data Analysis and Interpretation

Q. Are you aware about point of sale (ePoS) machine?

\begin{tabular}{|l|l|l|}
\hline Yes & No & Very few \\
\hline $\mathbf{1 4 \%}$ & $69 \%$ & $17 \%$ \\
\hline
\end{tabular}

Q. What do you think, this machine is

\begin{tabular}{|l|l|l|}
\hline Necessary & $\begin{array}{l}\text { Not } \\
\text { necessary }\end{array}$ & Don't know \\
\hline $\mathbf{5 0 \%}$ & $18 \%$ & $32 \%$ \\
\hline
\end{tabular}


Q. Is necessary of Aadhaar card and biometric cause problem for you

\begin{tabular}{|l|l|l|l|}
\hline Yes & No & $\begin{array}{l}\text { It is very } \\
\text { easy }\end{array}$ & $\begin{array}{l}\text { Don't } \\
\text { Know }\end{array}$ \\
\hline $\mathbf{2 5 \%}$ & $45 \%$ & $30 \%$ & $0 \%$ \\
\hline
\end{tabular}

Q. Are you aware about Direct Benefit Transfer (DBT)

\begin{tabular}{|l|l|l|l|}
\hline Yes & No & $\begin{array}{l}\text { Very } \\
\text { few }\end{array}$ & $\begin{array}{l}\text { Very } \\
\text { well }\end{array}$ \\
\hline $\mathbf{3 8 \%}$ & $15 \%$ & $56 \%$ & $11 \%$ \\
\hline
\end{tabular}

Q. What you think POS and DBT will save you for paying extra amount at the time of high fertilizer demand

\begin{tabular}{|l|l|l|}
\hline Yes & No & $\begin{array}{l}\text { Don't } \\
\text { Know }\end{array}$ \\
\hline $\mathbf{5 8 \%}$ & $35 \%$ & $7 \%$ \\
\hline
\end{tabular}

Q. How much POS machine is use full in giving information of real price of fertilizer?

\begin{tabular}{|l|l|l|l|}
\hline $\begin{array}{l}\text { Very } \\
\text { much }\end{array}$ & Normal & $\begin{array}{l}\text { Very } \\
\text { Less }\end{array}$ & $\begin{array}{l}\text { Don't } \\
\text { know }\end{array}$ \\
\hline $\mathbf{1 0 \%}$ & $17 \%$ & $0 \%$ & $73 \%$ \\
\hline
\end{tabular}

Q. May this system help in stopping black marketing?

\begin{tabular}{|l|l|l|}
\hline Yes & No & Can't say \\
\hline $\mathbf{6 0 \%}$ & $26 \%$ & $12 \%$ \\
\hline
\end{tabular}

Q. Is small fertilizer shops will be close in future due to high paper work and technical knowledge?

\begin{tabular}{|l|l|l|}
\hline Yes & No & Can't say \\
\hline $\mathbf{4 0 \%}$ & $32 \%$ & $43 \%$ \\
\hline
\end{tabular}

\section{Retailers' Data Analysis and Interpretation}

Q. Are you aware about point of sale (e POS) System in Fertilizer?

Every retailer are aware about point of sale machine, they all know POS machine is mandatory in the fertilizer selling.

Q. After implementation of POS system in fertilizer, what effect is on sales volume of fertilizer?

\begin{tabular}{|l|l|l|l|}
\hline Decrease & Increase & $\begin{array}{l}\text { Remain } \\
\text { unchanged }\end{array}$ & $\begin{array}{l}\text { Can't } \\
\text { say }\end{array}$ \\
\hline $\mathbf{3 9 \%}$ & $0 \%$ & $48 \%$ & $13 \%$ \\
\hline
\end{tabular}

Q. How much you are satisfied with Point of sale (ePOS) system in fertilizer?

\begin{tabular}{|l|l|l|l|}
\hline $\begin{array}{l}\text { Very } \\
\text { much }\end{array}$ & Moderate & Less & Unsatisfied \\
\hline $\mathbf{0 \%}$ & $32 \%$ & $39 \%$ & $29 \%$ \\
\hline
\end{tabular}

Q. Are you comfortable with the language option provided in the ePOS machine?

\begin{tabular}{|l|l|l|}
\hline Yes & No & Can't say \\
\hline $81 \%$ & $19 \%$ & $0 \%$ \\
\hline
\end{tabular}

Q. May this system help in removing unauthorized/fake retailers from the market?

\begin{tabular}{|c|c|c|}
\hline Yes & No & Can't say \\
\hline $\mathbf{3 5 \%}$ & $42 \%$ & $23 \%$ \\
\hline
\end{tabular}

Q. How much you are satisfied with the training facility provided by Fertilizer Company for operating the Point of Sale (PoS) machine?

\begin{tabular}{|l|l|l|}
\hline Excellent & Good & Poor \\
\hline $0 \%$ & $84 \%$ & $16 \%$ \\
\hline
\end{tabular}


Q. Is POS machine maintenance requires an extra cost and care?

According to every retailer there is extra cost and care are for the POS machine maintenance and they think this is extra burden for them.

Q. Is network connectivity hampering the functioning of POS machines and delaying in transactions?

There is a common problem with every retailers in operating the POS machines i.e. network connectivity. This problem is very common in the rural area. Sometime this problem also comes due to the electricity supply mainly in rural area.

Q. How much this scheme makes the retailers able in maintaining the stock report easier than earlier?

\begin{tabular}{|l|l|l|}
\hline Very much & Moderate & Can't say \\
\hline $68 \%$ & $26 \%$ & $6 \%$ \\
\hline
\end{tabular}

Q. Is it possible to record the fertilizer's transaction at individual consumer/farmer level?

\begin{tabular}{|l|l|l|}
\hline Yes & No & Can't say \\
\hline $\mathbf{7 7 \%}$ & $\mathbf{2 3 \%}$ & $\mathbf{0 \%}$ \\
\hline
\end{tabular}

\section{Findings of the study}

Most of the Retailers found internet connectivity problem during operation of E-PoS machine. It is a very big problem in the operation of point of sale machine, it hamper the process of fertilizer selling.

Delay in acceptance of biometric identification / authentication of retailer as well as farmer.

Retailers have less knowledge about PoS machine so require more training to the retailers.

The sale process is taking 2-3 minutes or more time for a single farmer/customer.

It is difficult for the farmer to be personally present every time at the fertilizer retail store.

Lack of awareness among the farmers regarding point of sale machine so they don't carry their AADHAAR card for purchase fertilizer.

Due to age factor and lack of knowledge some dealers and retailers are not ready to use this system.

There is only one option of language i.e. English some retailer is not habitual with the English language so they face problem in the operation of PoS machine.

The equipment needs to be charged but there are problems of power availability in the rural area.

There is no auto update process in the PoS machine.

Most of the farmers think if this system starts properly and regular basis in the fertilizer marketing this will remove the black marketing and secure availability of fertilizer at pick period.

There no repairing point of PoS machine, if machine become damage in this situation the sale of fertilizer become hampered.

The farmers have expressed their happiness in availing the fertilizer at the government fixed price and also restricting the dealer from black marketing.

On the basis of above analysis and observation we conclude that the adoption of Aadhaar enabled distribution system in the fertilizer industries through ePoS machine. It is a good initiative taken by the government of India so that this system can be effective in the way of checking black marketing of fertilizers. 
But organizations and government facing different field issues such as network connectivity, irregular electricity supply and major problem is awareness regarding Aadhaar enabled distribution system. But lead fertilizer companies are playing active role to overcome these problem, they are organizing field awareness program, giving demonstration to the farmer.

Organizations also promoting case less transection for purchasing fertilizers. Farmers are happy with this system because this system will save their money and also helpful in stopping black marketing of fertilizer so that fertilizer will be available at the time of high fertilizer demand.

\section{References}

Annual report 2018-19 Department of fertilizer (GOI). https://pib.gov.in/Pressreleaseshare.aspx ? PRID=1579455.
Patil, V.C., Gelb, E., Maru, A., Yadaraju, N.T., Moni M. and MisraH. S. 2008 Adoption of Information and Communication Technology (ICT) for Agriculture: An Indian case study 5(3), 685-692.

Praveen, K.V., Aditya, K.S., Nithyashree, M. L. and Sharma A. 2009 Fertilizer subsidies in India: an insight to distribution and equity issues Fertilizer subsidies in India: an insight to distribution and equity issues.

Provisional Population Totals, Census of India 2011Cities having population 1 lakh and above" (PDF). Office of the Registrar General \& Census Commissioner, India. Archived from the originalpublication on 7 May 2012, 104-112.

Victoria, M. V. 2007Agricultural technology in Bangladesh: a study on non-farm labor and adoption by gender, 3(1) 228 235.

\section{How to cite this article:}

Ravi Kumar Raman, Ashish Singh and Manjeet Kumar Verma. 2020. Major Challenges in the Implementation of AADHAAR Enable Fertilizer System and Perception of Farmers and Retailers About ePoS (A Case Study of Kanpur District, Uttar Pradesh State). Int.J.Curr.Microbiol.App.Sci. 9(02): 2172-2179. doi: https://doi.org/10.20546/ijcmas.2020.902.245 